\title{
Synthesis of $N$-substituted Acridinediones and Polyhydroquinoline Derivatives in Refluxing Water
}

\section{Jing-Jing Xia * and Ke-Hua Zhang}

School of Materials and Chemical Engineering, Anhui University of Architecture, Hefei 230601, China; E-Mail: zhangkehua@aiai.edu.cn

* Author to whom correspondence should be addressed; E-Mail: xiajj@aiai.edu.cn; Tel.: +86-551-382-8100.

Received: 13 March 2012; in revised form: 24 April 2012 / Accepted: 28 April 2012 /

Published: 7 May 2012

\begin{abstract}
Acridinediones were synthesized by the one-pot Hantzsch condensation of an aromatic aldehyde, 5,5-dimethyl-1,3-cyclohexanedione, and aniline/4-methylaniline in refluxing water. This method has then been extended to the four-component reaction of an aromatic aldehyde, 5,5-dimethyl-1,3-cyclohexanedione, ethyl acetoacetate and ammonium acetate for the synthesis of polyhydroquinoline derivatives. This is an environmentally friendly and efficient procedure providing good to excellent yields.
\end{abstract}

Keywords: acridinedione; polyhydroquinoline; one-pot reaction; water

\section{Introduction}

1,4-Dihydropyridines as analogues of nicotinamide adenine dinucleotide (NADH) coenzymes exhibit a wide range of biological activities, such as calcium channel blocking, and today they are widely used in pharmacology [1]. Acridines which possess the 1,4-dihydropyridine parent nucleus have interesting pharmaceutical properties such as a positive iontropic effects promoting the entry of calcium to the intracellular space [2], and 1,8-(2H,5H)-acridinediones are known as laser dyes [3].

1,8-(2H,5H)-Acridinediones were synthesized by the adoption of the Hantzsch procedure, i.e., by the thermal reaction of 5,5-dimethyl-1,3-cyclohexanedione (dimedone) with an aldehyde and ammonia. Most of the methods reported previously usually require long reaction times, afford 1,4-dihydropyridines in relatively low yield, and suffer from utilizing harmful organic solvents in most cases [4-11]. 
On the other hand, with the increasing environmental concerns, green chemistry has attracted intensive attention in recent years. Multicomponent one-pot reactions as a kind of economical and efficient procedure has been widely used for the synthesis of heteroatom-containing compounds [12-14]. Moreover, organic reactions in water as the reaction medium, which represents a clean, economical, and environmental-safe protocol, has attracted considerable attention. We have already reported the one-pot synthesis of 10 -unsubstituted 1,8-(2H,5H)-acridinediones by the thermal reaction of 5,5-dimethyl-1,3-cyclohexanedione (dimedone) with an aldehyde and ammonium acetate in pure water without any additives [15]. In this paper, ammonium acetate has been replaced by aniline and 4-methylaniline for the synthesis of $N$-substituted 1,8-(2H,5H)-acridinediones by the Hantzsch reaction in refluxing water.

\section{Results and Discussion}

1,8-(2H,5H)-Acridinediones were synthesized by the one-pot three-component Hantzsch condensation for a designated time of paraformaldehyde, dimedone and $\mathrm{NH}_{4} \mathrm{HCO}_{3}$, or $\mathrm{NH}_{4} \mathrm{OAc}$, or aniline, or 4-methyl-aniline in refluxing water without any additives. The reaction times and yields are listed in Table 1.

Table 1. Reaction time and yield for the reaction of different amines/ammonium salts.

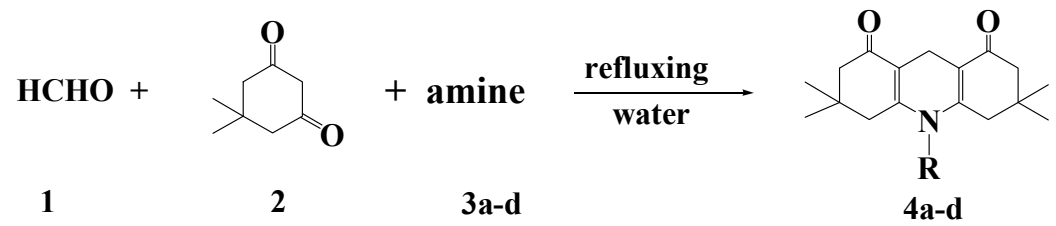

\begin{tabular}{llllll}
\hline Entry & Amine & Reaction time/min & Product & $\mathbf{R}$ & Yield / \% \\
\hline 1 & $\mathrm{NH}_{4} \mathrm{OAc}$ & $40 \mathrm{~min}$ & $\mathbf{4 a}$ & $\mathrm{H}$ & 86 \\
2 & $\mathrm{NH}_{4} \mathrm{HCO}_{3}$ & $40 \mathrm{~min}$ & $\mathbf{4 b}$ & $\mathrm{H}$ & 83 \\
3 & $\mathrm{C}_{6} \mathrm{H}_{5}-\mathrm{NH}_{2}$ & $90 \mathrm{~min}$ & $\mathbf{4 c}$ & $\mathrm{C}_{6} \mathrm{H}_{5}$ & 71 \\
4 & $4-\mathrm{CH}_{3}-\mathrm{C}_{6} \mathrm{H}_{5}-\mathrm{NH}_{2}$ & $90 \mathrm{~min}$ & $\mathbf{4 d}$ & $4-\mathrm{CH}_{3}-\mathrm{C}_{6} \mathrm{H}_{4}$ & 69 \\
\hline
\end{tabular}

${ }^{\mathrm{a}}$ Isolated yield of the pure product recrystallized from $75 \%$ aqueous ethanol.

From Table 1, one can see that the reaction yields of ammonium compounds (entry 1 and 2) are higher than for aromatic amines (entry 3 and 4). This is probably due to the lower solubility of the aromatic amines in water and lower reactivity than that of the ammonium compounds. It should be mentioned that the amount of the amine in the reactions was different. When an aromatic amine was used (entry 3 and 4), the molar ratio of $\mathbf{1}, \mathbf{2}$, and $\mathbf{3}$ was 1:2:1; when an ammonium compound was used (entry 1 and 2), the molar ratio of $\mathbf{1}, \mathbf{2}$, and $\mathbf{3}$ was 1:2:4. The increasing of the dosage of ammonium compound is because of the easy resolvability.

In order to obtain a higher yield, we tried to add a phase-transfer catalyst (PTC) to the reaction mixtures. Cetyltrimethylammonium bromide (CTAB) was previously applied by us to the aqueous Michael reaction of dimedone with chalcones [16], and now in this Hantzsch condensation of aldehyde, dimedone and aniline, addition of $10 \%$ mol of CTAB produced $\mathrm{N}$-substituted 1,8-(2H,5H)acridinediones in much better yield. The reaction yields, as well as the melting points for the Hantzsch reactions with the molar ratio of aromatic aldehydes $\mathbf{1}$, dimedone (2), and aniline or 4-methylaniline $\mathbf{3}$, 
and CTAB as 1:2:1:0.1 in refluxing water are listed in Table 2. Reaction times are all 90 min. In our protocol, no organic solvents were used during the reaction process. Furthermore, since the product is solid and precipitates out from the reaction mixtures, the work-up procedure involves simple filtration. The desired products of high purity were obtained by column chromatography or recrystallization.

Table 2. Yields and melting points for the one-pot synthesis of $N$-substituted acridinediones.

\begin{tabular}{|c|c|c|c|c|c|}
\hline & & 2 & 3c-d & 5a-n & \\
\hline Entry & $\mathbf{R}$ & $\mathbf{R}^{\prime}$ & Product & Yield / \% ${ }^{a}$ & m.p. (lit.) $/{ }^{\circ} \mathbf{C}$ \\
\hline 1 & $\mathrm{C}_{6} \mathrm{H}_{5}$ & $\mathrm{C}_{6} \mathrm{H}_{5}$ & $5 a$ & 80 & $220-222(200-205)[17]$ \\
\hline 2 & $4-\mathrm{Cl}-\mathrm{C}_{6} \mathrm{H}_{4}$ & $\mathrm{C}_{6} \mathrm{H}_{5}$ & $5 \mathbf{b}$ & 86 & $243-245(233-235)[18]$ \\
\hline 3 & $4-\mathrm{CN}-\mathrm{C}_{6} \mathrm{H}_{4}$ & $\mathrm{C}_{6} \mathrm{H}_{5}$ & $5 c$ & 88 & $265-267$ \\
\hline 4 & $4-\mathrm{NO}_{2}-\mathrm{C}_{6} \mathrm{H}_{4}$ & $\mathrm{C}_{6} \mathrm{H}_{5}$ & 5d & 85 & $281-282(216-218)[17]$ \\
\hline 5 & $3-\mathrm{NO}_{2}-\mathrm{C}_{6} \mathrm{H}_{4}$ & $\mathrm{C}_{6} \mathrm{H}_{5}$ & $5 e$ & 84 & $272-274(276-278)[19]$ \\
\hline 6 & $3,4-\mathrm{Cl}_{2}-\mathrm{C}_{6} \mathrm{H}_{3}$ & $\mathrm{C}_{6} \mathrm{H}_{5}$ & $5 f$ & 90 & $274-275$ \\
\hline 7 & $4-\mathrm{CH}_{3} \mathrm{O}-\mathrm{C}_{6} \mathrm{H}_{4}$ & $\mathrm{C}_{6} \mathrm{H}_{5}$ & $5 g$ & 70 & $291-293(290-291)[20]$ \\
\hline 8 & $\mathrm{C}_{6} \mathrm{H}_{5}$ & $4-\mathrm{CH}_{3}-\mathrm{C}_{6} \mathrm{H}_{4}$ & $5 \mathrm{~h}$ & 81 & $261-263(264-266)[21]$ \\
\hline 9 & $4-\mathrm{Cl}-\mathrm{C}_{6} \mathrm{H}_{4}$ & $4-\mathrm{CH}_{3}-\mathrm{C}_{6} \mathrm{H}_{4}$ & $5 \mathbf{i}$ & 85 & $270-272(271-272)[21]$ \\
\hline 10 & $4-\mathrm{CN}-\mathrm{C}_{6} \mathrm{H}_{4}$ & $4-\mathrm{CH}_{3}-\mathrm{C}_{6} \mathrm{H}_{4}$ & $5 \mathbf{j}$ & 88 & $268-270(273-275)[21]$ \\
\hline 11 & $4-\mathrm{NO}_{2}-\mathrm{C}_{6} \mathrm{H}_{4}$ & 4- $\mathrm{CH}_{3}-\mathrm{C}_{6} \mathrm{H}_{4}$ & $5 \mathbf{k}$ & 83 & $>300(>300)[22]$ \\
\hline 12 & $3-\mathrm{NO}_{2}-\mathrm{C}_{6} \mathrm{H}_{4}$ & $4-\mathrm{CH}_{3}-\mathrm{C}_{6} \mathrm{H}_{4}$ & 51 & 85 & $281-283(283-284)[23]$ \\
\hline 13 & $3,4-\mathrm{Cl}_{2}-\mathrm{C}_{6} \mathrm{H}_{3}$ & $4-\mathrm{CH}_{3}-\mathrm{C}_{6} \mathrm{H}_{4}$ & $5 \mathrm{~m}$ & 88 & $253-255(250-252)[23]$ \\
\hline 14 & $4-\mathrm{CH}_{3} \mathrm{O}-\mathrm{C}_{6} \mathrm{H}_{4}$ & $4-\mathrm{CH}_{3}-\mathrm{C}_{6} \mathrm{H}_{4}$ & $5 n$ & 72 & $280-282(281-283)[23]$ \\
\hline
\end{tabular}

${ }^{\mathrm{a}}$ Isolated yield of the pure product recrystallized from $75 \%$ aqueous ethanol.

From Table 2, one can see that all these reactions gave good to excellent yields, reflecting that dimedone has high solubility in water and high reactivity. The yields of $N$-substituted acridinediones for the aromatic aldehydes with an electron-withdrawing group are higher than those for aromatic aldehydes with electron-donating groups. We also tried 3,4-dimethoxybenzaldehyde, but the reaction yield is lower than $50 \%$.

We have attempted to extend the above methods to different 1,3-dicarbonyl compounds for the synthesis of unsymmetrically substituted 1,4-dihydropyridines such as polyhydroquinoline derivatives. Ethyl acetoacetate and 1,3-cyclohexanedione smoothly undergo a four-component reaction with aromatic aldehyde and ammonium acetate to produce polyhydroquinoline derivatives in refluxing water catalyzed by CTAB. Because of the lower activity for the synthesis of unsymmetrically substituted 1,4-dihydropyridines than the symmetrically substituted 1,4-dihydropyridines, ammonium acetate was used to replace the aromatic amines. The reaction yields, as well as the melting points for the Hantzsch reaction with the molar ratio of aromatic aldehydes 1, dimedone (2), ethyl acetoacetate (6), ammonium acetate (3), and $\mathrm{CTAB}$ as 1:1:1:4:0.1 in refluxing water are listed in Table 3 . Reaction times are all $90 \mathrm{~min}$. 
Table 3. Yields and melting points for the one-pot synthesis of polyhydroquinoline derivatives.

\begin{tabular}{|c|c|c|c|c|}
\hline 1 & 3 & & 6 & $7 a-d$ \\
\hline Entry & $\mathbf{R}$ & Product & Yield $/ \%{ }^{a}$ & m.p. (lit.) $/{ }^{\circ} \mathbf{C}$ \\
\hline 1 & $\mathrm{C}_{6} \mathrm{H}_{5}$ & $7 a$ & 85 & $224-226(228-229)[24]$ \\
\hline 2 & $4-\mathrm{CH}_{3} \mathrm{O}-\mathrm{C}_{6} \mathrm{H}_{4}$ & $7 b$ & 81 & $257-259(260-262)[24]$ \\
\hline 3 & $4-\mathrm{Cl}-\mathrm{C}_{6} \mathrm{H}_{4}$ & $7 c$ & 90 & $244-266(245-246)[24]$ \\
\hline 4 & $4-\mathrm{NO}_{2}-\mathrm{C}_{6} \mathrm{H}_{4}$ & $7 d$ & 88 & $242-244(241-242)[24]$ \\
\hline
\end{tabular}

${ }^{\mathrm{a}}$ Isolated yield of the pure product recrystallized from $75 \%$ aqueous ethanol.

Among the acridinediones and polyhydroquinoline products $\mathbf{5 c}$ and $\mathbf{5 f}$ were unknown compounds and were characterized by their melting point, IR, ${ }^{1} \mathrm{H}-\mathrm{NMR},{ }^{13} \mathrm{C}-\mathrm{NMR}$ spectra and elemental analysis. Structures of known compounds were confirmed by comparison of their melting points and ${ }^{1} \mathrm{H}-\mathrm{NMR}$ spectra with the reported data. It should be mentioned that the melting point of $\mathbf{5 d}$ was obviously higher than the reported in the literature [17]. However, our measured IR, ${ }^{1} \mathrm{H}-\mathrm{NMR},{ }^{13} \mathrm{C}-\mathrm{NMR}$ spectral data and elemental analysis are consistent with the series of acridinediones products, exhibiting the same identities. The different $\mathrm{mp}$ might be ascribed to the presence of an impurity or solvent in product 5d from the reported literature, because even a trace amount could have a great effect on the m.p. of a compound with high m.p.

\section{Experimental}

\subsection{General}

${ }^{1} \mathrm{H}-\mathrm{NMR}$ spectra were recorded on a Bruker Avance-400 (400 MHz) spectrometer (Bruker, Switzerland), and chemical shifts $(\delta)$ are reported in parts per million relative to tetramethylsilane and coupling constants $(J)$ in Hz. Splitting patterns are designated as s, singlet; d, doublet; br, broad. ${ }^{13} \mathrm{C}-\mathrm{NMR}$ spectra were recorded on the same spectrometer (at $100 \mathrm{MHz}$ ) with complete proton decoupling, and chemical shifts are reported in parts per million relative to the solvent resonance used as the internal standard $\left(\mathrm{CDCl}_{3}, \delta 77.16 \mathrm{ppm}\right.$; DMSO-d6, $\left.\delta 39.52 \mathrm{ppm}\right)$. IR spectra were taken on a Bruker Vector-22 spectrometer (Bruker, Switzerland) in $\mathrm{KBr}$ pellets and are reported in $\mathrm{cm}^{-1}$. Melting points were determined on an XT-4 apparatus (Beijing Tech Instrument Co., Beijing, China). Analytical TLC and column chromatography were performed on silica gel GF254 and silica gel H60, respectively.

\subsection{Typical Procedure for the Synthesis of Acridinediones: 3,3,6,6-Tetramethyl-9,10-diphenyl-} 3,4,6,7,9,10-hexahydro-1,8-(2H,5H)-acridinedione (5a)

A mixture of $1 \mathbf{a}(106.1 \mathrm{mg}, 1 \mathrm{mmol}), 2$ (280.4 mg, $2 \mathrm{mmol}), 3 \mathbf{c}(93.1 \mathrm{mg}, 1 \mathrm{mmol})$ and CTAB (36.4 $\mathrm{mg}, 0.1 \mathrm{mmol})$ in water $(4 \mathrm{~mL})$ was vigorously stirred under reflux. The reaction was completed after $90 \mathrm{~min}$, as monitored by TLC. Due to the high yields of 5a, the work-up procedure involved simple filtration and washing twice with water $(10 \mathrm{~mL})$. The obtained solid products were nearly pure. 
The desired product of high purity were further achieved by column chromatography with petroleum ether/ethyl acetate or recrystallization from $75 \%$ aqueous ethanol.

3,3,6,6-Tetramethyl-9-(4-cyanophenyl)-10-phenyl-3,4,6,7,9,10-hexahydro-1,8-(2H,5H)-acridinedione (5c). IR (KBr): v 2956 (s), 2872 (m), 2223 (m), 1643 (s), 1576 (s), 1492 (m), 1362 (s), 1297 (w), 1262 (m), $1174(\mathrm{w}), 1144(\mathrm{~m}), 1122(\mathrm{w}), 1000(\mathrm{~m}), 851$ (s), 704 (s), 569 (s) cm ${ }^{-1} ;{ }^{1} \mathrm{H}-\mathrm{NMR}\left(\mathrm{CDCl}_{3}\right): \delta 0.79$ (s, 6H, $\left.\mathrm{CH}_{3}\right), 0.95\left(\mathrm{~s}, 6 \mathrm{H}, \mathrm{CH}_{3}\right), 1.85\left(\mathrm{~d}, J=17.5 \mathrm{~Hz}, 2 \mathrm{H}, \mathrm{CH}_{2}\right), 2.11\left(\mathrm{~d}, J=17.5 \mathrm{~Hz}, 2 \mathrm{H}, \mathrm{CH}_{2}\right), 2.12$ (d, $\left.J=16.2 \mathrm{~Hz}, 2 \mathrm{H}, \mathrm{CH}_{2}\right), 2.21$ (d, $\left.J=16.2 \mathrm{~Hz}, 2 \mathrm{H}, \mathrm{CH}_{2}\right), 5.31(\mathrm{~s}, 1 \mathrm{H}, \mathrm{CH}), 7.25(\mathrm{~d}, J=8.0 \mathrm{~Hz}, 2 \mathrm{H}$, $\operatorname{ArH}), 7.54$ (d, $J=8.6 \mathrm{~Hz}, 2 \mathrm{H}, \mathrm{ArH}), 7.58$ (d, $J=8.0 \mathrm{~Hz}, 2 \mathrm{H}, \mathrm{ArH}), 7.59$ (m, 3H, ArH); ${ }^{13} \mathrm{C}-\mathrm{NMR}$ $\left(\mathrm{CDCl}_{3}\right): \delta 195.8,151.6,150.6,138.6,131.9,129.7,128.8,119.3,113.4,109.5,50.1,41.8,33.7,32.4$, 29.6, 26.7; Anal. Calcd. for $\mathrm{C}_{30} \mathrm{H}_{30} \mathrm{~N}_{2} \mathrm{O}_{2}$ : C, 79.97; H, 6.71; N, 6.22; Found: C, 79.97; H, 6.80; N, 6.17.

\section{3,3,6,6-Tetramethyl-9-(4-nitrophenyl)-10-phenyl-3,4,6,7,9,10-hexahydro-1,8-(2H,5H)-acridinedione}

(5d). IR (KBr): v 2956 (m), 1635 (s), 1594 (w), 1514 (m), 1349 (s), 1224 (m), 1176 (w), 1144 (w), $1113(\mathrm{w}), 1003(\mathrm{~m}), 864(\mathrm{w}), 830(\mathrm{w}), 703(\mathrm{~m}), 572(\mathrm{w}), 513(\mathrm{w}) \mathrm{cm}^{-1} ;{ }^{1} \mathrm{H}-\mathrm{NMR}\left(\mathrm{CDCl}_{3}\right): \delta 0.72$ (s, $\left.6 \mathrm{H}, \mathrm{CH}_{3}\right), 0.88\left(\mathrm{~s}, 6 \mathrm{H}, \mathrm{CH}_{3}\right), 1.77$ (d, $\left.J=17.5 \mathrm{~Hz}, 2 \mathrm{H}, \mathrm{CH}_{2}\right), 2.03$ (d, $\left.J=17.5 \mathrm{~Hz}, 2 \mathrm{H}, \mathrm{CH}_{2}\right), 2.04$ (d, $\left.J=16.3 \mathrm{~Hz}, 2 \mathrm{H}, \mathrm{CH}_{2}\right), 2.14\left(\mathrm{~d}, J=16.3 \mathrm{~Hz}, 2 \mathrm{H}, \mathrm{CH}_{2}\right), 5.28(\mathrm{~s}, 1 \mathrm{H}, \mathrm{CH}), 7.18$ (d, $J=8.2 \mathrm{~Hz}, 2 \mathrm{H}$, $\operatorname{ArH}), 7.53(\mathrm{~d}, J=8.2 \mathrm{~Hz}, 2 \mathrm{H}, \operatorname{ArH}), 7.54(\mathrm{~s}, 1 \mathrm{H}, \operatorname{ArH}), 7.55$ (d, $J=8.8 \mathrm{~Hz}, 2 \mathrm{H}, \operatorname{ArH}), 8.05(\mathrm{~d}$, $J=8.8 \mathrm{~Hz}, 2 \mathrm{H}, \mathrm{ArH}) ;{ }^{13} \mathrm{C}-\mathrm{NMR}\left(\mathrm{CDCl}_{3}\right): \delta 195.6,153.6,150.4,146.2,138.7,129.7,128.8,123.5$, 113.6, 50.1, 41.9, 33.6, 32.4, 29.6, 26.7; Anal. Calcd. for $\mathrm{C}_{29} \mathrm{H}_{30} \mathrm{~N}_{2} \mathrm{O}_{4}$ : C, 74.02; H, 6.43; N, 5.95; Found: C, 73.63; H, 6.43; N, 5.91 .

3,3,6,6-Tetramethyl-9-(3,4-dichlorophenyl)-10-phenyl-3,4,6,7,9,10-hexahydro-1,8-(2H,5H)-acridinedione (5f). IR (KBr): v 2962 (m), 2948 (m), 1650 (s), 1638 (s), 1573 (m), 1471 (m), 1360 (s), 1224 (s), $1143(\mathrm{~m}), 1027$ (w), $1002(\mathrm{w}), 878(\mathrm{~m}), 704(\mathrm{~s}), 574(\mathrm{~m}) \mathrm{cm}^{-1} ;{ }^{1} \mathrm{H}-\mathrm{NMR}\left(\mathrm{CDCl}_{3}\right): \delta 0.80\left(\mathrm{~s}, 6 \mathrm{H}, \mathrm{CH}_{3}\right)$, $0.93\left(\mathrm{~s}, 6 \mathrm{H}, \mathrm{CH}_{3}\right), 1.83$ (d, $\left.J=17.6 \mathrm{~Hz}, 2 \mathrm{H}, \mathrm{CH}_{2}\right), 2.08$ (d, J=17.6 Hz, 2H, $\left.\mathrm{CH}_{2}\right), 2.17\left(\mathrm{~m}, 4 \mathrm{H}, \mathrm{CH}_{2}\right)$, $5.21(\mathrm{~s}, 1 \mathrm{H}, \mathrm{CH}), 7.22(\mathrm{~m}, 2 \mathrm{H}, \mathrm{ArH}), 7.28(\mathrm{~m}, 2 \mathrm{H}, \mathrm{ArH}), 7.50(\mathrm{~s} 1 \mathrm{H}, \mathrm{ArH}), 7.56$ (m, 3H, ArH);

${ }^{13} \mathrm{C}-\mathrm{NMR}\left(\mathrm{CDCl}_{3}\right): \delta 195.7,150.3,146.6,138.7,131.9,130.0,129.9,129.6,127.6,113.8,50.1,41.8$, 32.4, 29.7, 26.8; Anal. Calcd. for $\mathrm{C}_{29} \mathrm{H}_{29} \mathrm{Cl}_{2} \mathrm{NO}_{2}$ : C, 70.44; H, 5.91; N, 2.83; Found: C, 70.40; H, 6.01; $\mathrm{N}, 2.78$.

\section{Conclusions}

In summary, acridinediones and polyhydroquinoline derivatives were synthesized by the one-pot Hantzsch condensation of an aromatic aldehyde, 5,5-dimethyl-1,3-cyclohexanedione, ethyl acetoacetate and amine. It represents a straightforward protocol for the eco-friendly and efficient synthesis of a series of 1,4-dihydropyridines with potential biological activities.

\section{Supplementary Materials}

Supplementary materials can be accessed at: http://www.mdpi.com/1420-3049/17/5/5339/s1. 


\section{Acknowledgments}

We are grateful for financial support from the Natural Science Foundation of Anhui Province Education Department (KJ2010B049) and Anhui Provincial Natural Science Foundation (1208085QB24).

\section{References and Notes}

1. Stilo, A.D.; Visentin, S.; Cena, C.; Gasco, A.M.; Ermondi, G.; Gasco, A. New 1,4-dihydropyridines conjugated to furoxanyl moieties, endowed with both nitric oxide-like and calcium channel antagonist vasodilator activities. J. Med. Chem. 1998, 41, 5393-5401.

2. Janis, R.A.; Triggle, D.J. New developments in $\mathrm{Ca}^{2+}$ channel antagonists. J. Med. Chem. 1993, 26, 775-785.

3. Kaya, M.; Yıldırır, Y.; Türker, L. Synthesis and laser activity of halo-acridinedione derivatives. J. Heterocyclic Chem. 2009, 46, 294-297.

4. Dabiri, M.; Baghbanzadeh, M.; Arzroomchilar, E. 1-Methylimidazolium triflouroacetate ([Hmim]TFA): An efficient reusable acidic ionic liquid for the synthesis of 1,8-dioxooctahydroxanthenes and 1,8-dioxo-decahydroacridines. Catal. Commun. 2008, 9, 939-942.

5. Shi, D.Q.; Ni, S.N.; Yang, F.; Shi, J.W.; Dou, G.L.; Li, X.Y.; Wang, X.S. An efficient synthesis of polyhydroacridine derivatives by the three-component reaction of aldehydes, amines and dimedone in ionic liquid. J. Heterocycl. Chem. 2008, 45, 653-660.

6. Kumara, D.; Sandhu, J.S. Efficient, solvent-free, microwave-enhanced condensation of 5,5-dimethyl-1,3-cyclohexanedione with aldehydes and imines using libr as inexpensive, mild catalyst. Synth. Commun. 2010, 40, 510-517.

7. Venkatesan, K.; Pujari, S.S.; Srinivasan, K.V. Proline-catalyzed simple and efficient synthesis of 1,8-dioxo-decahydroacridines in aqueous ethanol medium. Synth. Commun. 2009, 39, 228-241.

8. Niknam, K.; Panahi, F.; Saberi, D.; Mohagheghnejad, M. Silica-bonded S-sulfonic acid as recyclable catalyst for the synthesis of 1,8-dioxo-decahydroacridines and 1,8-dioxooctahydroxanthenes. J. Heterocycl. Chem. 2010, 47, 292-300.

9. Kidwai, M.; Bhatnagar, D. Ceric ammonium nitrate (CAN) catalyzed synthesis of $n$-substituted decahydroacridine-1,8-diones in PEG. Tetrahedron Lett. 2010, 51, 2700-2703.

10. Shi, D.Q.; Shi, J.W.; Yao, H. Clean synthesis of 9,10-diarylacridine derivatives in aqueous media. Chin. J. Org. Chem. 2009, 29, 239-244.

11. Shi, D.Q.; Mou, J.; Zhuang, Q.Y.; Wang, X.S. Synthesis of ethyl 2,7,7-trimethyl-5-oxo-4-aryl1,4,5,6,7,8-hexahydroquinoline-3-carboxylate in water. Chin. J. Org. Chem. 2004, 24, 1569-1572.

12. Ramazani, A.; Rezaei, A. Novel one-pot, four-component condensation reaction: An efficient approach for the synthesis of 2,5-disubstituted 1,3,4-oxadiazole derivatives by a Ugi-4CR/aza-wittig sequence. Org. Lett. 2010, 12, 2852-2855.

13. Ramazani, A.; Karimi, Z.; Souldozi, A.; Ahmadi, Y. Four-component synthesis of 1,3,4-oxadiazole derivatives from $n$-isocyaniminotriphenylphosphorane, aromatic carboxylic acids, aromatic bis-aldehydes, and secondary amines. Turk. J. Chem. 2012, 36, 81-91. 
14. Ramazani, A.; Rouhani, M.; Rezaei, A.; Shajari, N.; Souldozi, A. The reaction of ( $n$-isocyanimino)triphenylphosphorane with biacetyl in the presence of aromatic carboxylic acids: Efficient one-pot three-component reaction for the synthesis of 3-(5-aryl-1,3,4-oxadiazol-2-yl)-3hydroxybutan-2-one derivatives. Helv. Chim. Acta 2011, 94, 282-288.

15. Wang, G.W.; Xia, J.J.; Miao, C.B.; Wu, X.L. Environmentally friendly and efficient synthesis of various 1,4-dihydropyridines in pure water. Bull. Chem. Soc. Jpn. 2006, 79, 454-459.

16. Wang, G.W.; Lu, Q.Q.; Xia, J.J. Three types of products obtained unexpectedly from the reaction of dimedone with chalcones. Eur. J. Org. Chem. 2011, 4429-4438.

17. Luo, H.; Kang, Y.; Nie, H.; Yang, L. Fe ${ }^{3+}$-montmorillonite: An efficient solid catalyst for one-pot synthesis of decahydroacridine derivatives. J. Chin. Chem. Soc. 2008, 55, 1280-1285.

18. Shi, D.Q.; Shi, J.W.; Yao, H. Three-component one-pot synthesis of polyhydroacrodine derivatives in aqueous media. Synth. Commun. 2009, 39, 664-675.

19. Das, B.; Thirupathi, P.; Mahender, I.; Saidi Reddy, V.; Rao, Y.K. Amberlyst-15: An efficient reusable heterogeneous catalyst for the synthesis of 1,8-dioxo-octahydroxanthenes and 1,8-dioxodecahydroacridines. J. Molecular Catal. A: Chem. 2006, 247, 233-239.

20. Tang, Z.Q.; Chen, Y.; Liu, C.N.; Cai, K.Y.; Tu, S.J. A green procedure for the synthesis of 1,8-dioxodecahydroacridine derivatives under microwave irradiation in aqueous media without catalyst. J. Heterocycl. Chem. 2010, 47, 363-367.

21. Shen, Y.B.; Wang, G.W. Solvent-free synthesis of xanthenediones and acridinediones. ARKIVOC 2008, $x v i, 1-8$.

22. Tu, S.; Li, T.; Zhang, Y.; Shi, F.; Xu, J.; Wang, Q.; Zhang, J.; Zhu, X.; Jiang, B.; Jia, R.; Zhang, J. New reaction of schiff base with dimedone: New method for the acridine derivatives under microwave irradiation. J. Heterocycl. Chem. 2007, 44, 83-88.

23. Shen, W.; Wang, L.M.; Tian, H.; Tang, J.; Yu, J.J. Brønsted acidic imidazolium salts containing perfluoroalkyl tails catalyzed one-pot synthesis of 1,8-dioxo-decahydroacridines in water. J. Fluorine Chem. 2009, 130, 522-527.

24. Bandgar, B.P.; More, P.E.; Kamble, V.T.; Totre, J.V. Synthesis of polyhydroquinoline derivatives under aqueous media. ARKIVOC 2008, $x v, 1-8$.

Sample Availability: Samples of the compounds $\mathbf{5 a}-\mathbf{n}, \mathbf{7 a}-\mathbf{d}$ are available from the authors.

(C) 2012 by the authors; licensee MDPI, Basel, Switzerland. This article is an open access article distributed under the terms and conditions of the Creative Commons Attribution license (http://creativecommons.org/licenses/by/3.0/). 